\title{
If I ran the ED (with apologies to Dr. Seuss) Dr. Seuss used by permission from Dr. Seuss Enterprises, L.P.
}

\section{Nalin Ahluwalia, MD}

I will see them here.

I will see them there.

I will see them in a chair.

I will see them anywhere.

I can work the ED after 3 years or 5 . My job is to keep the patients alive. I will see them young and old. I will see them if it's just a cold.

I see the sick, I see the well. I see the old with dizzy spells.

I see the ones who have chest pain. I see the ones with secondary gain.

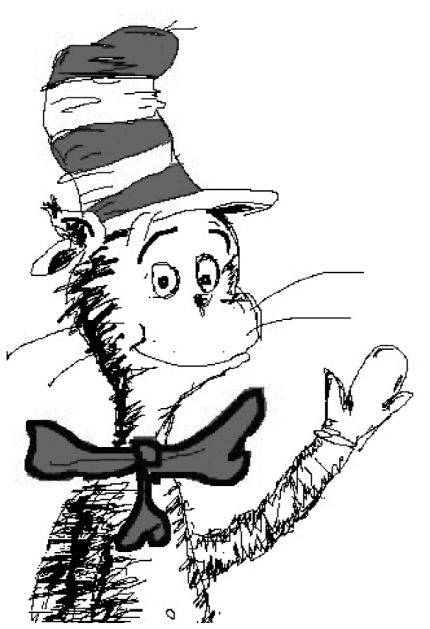

I really don't know what to do. Three-hour wait for CTAS-2. EMS is in off-load delay. Thank God for the AFA!

Room 16 thinks she's from MARS.

Resus has a probable SARS. Agency has staffed room 1. I think my orders will not get done.

I will see them here or there. I will see them in a chair. I will see them on the floor. And I will send them out the DOOR!
Acknowledgement: The author would like to thank Vandana Ahluwalia, without whose assistance this would not be possible.

Competing interests: None declared.

Keywords: humour and humanity

Chief and Clinical Director, Emergency Medicine Program, York Central Hospital, Richmond Hill, Ont.

Submitted Apr. 14, 2008; Accepted May 11, 2008

This article has not been peer reviewed.

CJEM 2009;11(4):394
Correspondence to: Dr. Nalin Ahluwalia, Oakville Trafalgar Memorial Hospital, 327 Reynolds St., Oakville ON L6J 3L7; nalins@rocketmail.com 